\title{
CEREZEN DEVICE PROVIDES TREATMENT FOR TEMPOROMANDIBULAR JOINT DISORDERS DAY AND NIGHT
}

A recent survey conducted amongst UK dental professionals about their success treating temporomandibular joint disorder found a concerning $80 \%$ of respondents had patients suffering from TMJD whom they are unable to help. This is disquieting since 25\% of adults worldwide experience the condition at some point in their lives. ${ }^{1-4}$

It has long been recommended that initial therapy for TMD should be conservative, non-invasive and reversible, and the most widely adopted treatment option to date has been the intraoral stabilisation splint. However, intraoral stabilisation splints cannot be worn while eating or drinking, and they also affect speech, so patients predominantly use them at night leading to a search for an alternative solution for daytime pain relief which does not impact on their ability to speak and eat and is less 'obvious' and obtrusive.

An entirely new and clinicallyproven treatment has recently become available to UK dentists. The Cerezen device is an innovative, custommade in-ear device that relieves the pain and symptoms of temporomandibular disorders. As well as significant efficacy in reducing a patient's pain, Cerezen is safe, non-invasive, comfortable and discreet, enabling it to be worn day and night - greatly improving patient compliance levels.

The Cerezen device takes a different approach in treating TMJD. The ear canal is located very close to the temporomandibular joint (TMJ) and the volume of the ear canal increases when the jaw is opened through movements such as chewing, smiling, and speaking. The Cerezen device uses this anatomical change to provide a unique near field treatment for TMJD.

The safety and clinical effectiveness of the Cerezen device was established in a pivotal, prospective, three-month, randomised, controlled clinical trial (registered at ClinicalTrials.gov: NCT00815776) ${ }^{5}$ that included patients with research

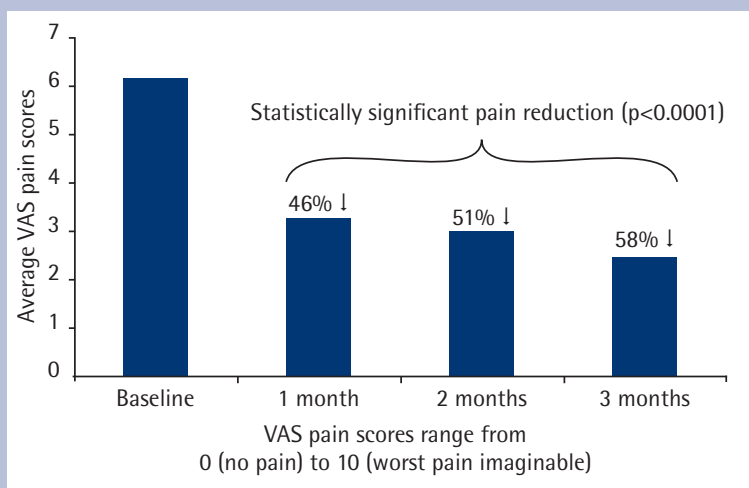

Fig. 1 Cerezen average VAS pain score reduction from baseline diagnostic criteria for temporomandibular disorders (RDC/ TMD) diagnoses of myofascial pain (1), disc displacement with reduction (II-a), and/or arthralgia (Ill-a); and a screening VAS (visual analog scale) pain score of $>4$ (on a scale of 0 to 10). The Cerezen device produced a statistically significant reduction in pain within the first month of treatment, with further reduction observed through the duration of the study (Fig. 1).

The Cerezen device was also demonstrated in the pivotal clinical trial to be statistically significantly noninferior to custom-fit flat plane occlusal appliances (the most widely used current treatment for TMD). No unanticipated adverse device effects or serious adverse events were reported during the study, and there were no reports of diminished hearing acuity in patients treated with the device. The comfort of the Cerezen device was exemplified in the study by the median 22.3 hours per day it was worn during the third month of the clinical trial. Patients in the study also reported very high global satisfaction, with $100 \%$ of subjects in the Cerezen treatment group indicating excellent $(71 \%)$ or good $(29 \%)$ overall satisfaction with the device.

Dr Lance Knight of BUPA Dental Centre, Manchester (pictured) is one of the first

Cerezen prescribers in the UK: 'At first I was sceptical; it sounds strange when you first hear that you are able to offer a patient a jaw treatment through the ear. I was particularly interested in the fact that

A knight in shining armour rides to the rescue of his TMJ patients the treatment is, like a splint, totally reversible. If it doesn't work, patients can simply remove it. With occlusal equibrilation, which had always been another option, there is no going back. Cerezen is a fantastic tool to have to offer to TMJ sufferers.'

To learn about how easy it is to integrate the Cerezen device into your practice workflow and help your patients relieve their pain and symptoms, call 08000488446 or visit www.cerezen.co.uk.

1. Macfarlane TV, Blinkhorn A S, Davies R $M$, Kincey J, Worthington H V. Oro-facial pain in the community: prevalence and associated impact. Community Dent Oral Epidemiol 2002; 30: 52-60.

2. Johansson $A$, Unell $L$, Carlsson $G E_{\text {, }}$ Soderfeldt B, Halling A. Gender difference in symptoms related to temporomandibular disorders in a population of 50 year old subjects. J Orofac Pain 2003; 17: 29-35.

3. Doyle N, Chiu CY, Haggard R, Gatchel R J Wiggins N. The prevalence of temporomandibular joint and muscle disorders in African Americans. J Applied Biobehavioral Res 2012; 17: 249-260.

4. Goulet J P, Lavigne G J, Lund J P. Jaw pain prevalence among French-speaking Canadians in Quebec and related symptoms of temporomandibular disorders. J Dent Res 1995; 74: 1738-1744.

5. Tavera A T, Montoya M C, Calderón E F, Gorodezky G, Wixtrom R N. Approaching temporomandibular disorders from a new direction: a randomized controlled clinical trial of the TMDes ear system. Cranio 2012; 30: 172-182. 